УДК 316.42

DOI 10.52575/2712-746X-2021-46-4-799-800

\title{
Ценностные основания гражданской активности: социологический анализ
}

\author{
Хрипкова Д.В. \\ Белгородский государственный национальный исследовательский университет \\ Россия, 308015, г. Белгород, ул. Победы, д. 85 \\ E-mail: davtyan@bsu.edu.ru
}

\begin{abstract}
Аннотация. Представлен анализ роли ценностных установок в реализации практик гражданской активности. Отмечено, что в последнее десятилетие уделяется особое внимание изучению влияния социокультурных факторов (ценностей, идей, традиций, религии и т.д.) на общественные процессы и взаимодействия. Под гражданской активностью в рамках исследования понимается деятельность индивидов, социальных групп, институтов гражданского общества по достижению общих для большинства целей, основанная на единстве ценностных установок, взаимном доверии, солидарности и ответственности. Сделан вывод о необходимости поиска источников солидаризации и консолидации в целях преодоления дефицита солидаристских ценностей в современном обществе.
\end{abstract}

Ключевые слова: ценности, доверие, гражданская активность, солидарность, консолидация, справедливость

Благодарности: исследование выполнено за счет гранта Российского научного фонда № 21-18-00150.

Для цитирования: Хрипкова Д.В. 2021. Ценностные основания гражданской активности: социологический анализ. NOMOTHETIKA: Философия. Социология. Право, 46 (4): 799-800. DOI: $10.52575 / 2712-746 \mathrm{X}-2021-46-4-799-800$

\section{The Value Bases of Civic Activity: A Sociological Analysis}

\author{
Diana V. Khripkova \\ Belgorod National Research University \\ 85 Pobeda St, Belgorod 308015, Russian Federation \\ E-mail: davtyan@bsu.edu.ru
}

\begin{abstract}
Annotation. The article analyzes the role of value attitudes in the implementation of civic engagement practices. It is noted that in modern sociological science, in the last decade, special attention has been paid to the study of the influence of socio-cultural factors (values, ideas, traditions, religion, etc.) on social processes and interactions. Within the framework of the study, civic engagement is understood as the activity of individuals, social groups, and civil society institutions to achieve common goals for most, based on the unity of value attitudes, mutual trust, solidarity and responsibility. As a result of the analysis, it is concluded that it is necessary to search for sources of solidarization and consolidation in order to overcome the deficit of solidaristic values in modern society.
\end{abstract}

Keywords: values, trust, civic engagement, solidarity, consolidation, justice

Acknowledgements: The research was carried out at the expense of the Russian Science Foundation grant No. 21-18-00150, https://rscf.ru/project/21-18-00150/

For citation: Khripkova D.V. 2021. The Value Bases of Civic Activity: A Sociological Analysis. NOMOTHETIKE: Philosophy. Sociology. Law, 46(4): 799-800 (in Russian). DOI: 10.52575/2712746X-2021-46-4-799-800 
В последнее десятилетие социологи уделяют особое внимание изучению влияния социокультурных факторов (ценностей, идей, традиций, религии и т.д.) на общественные процессы и взаимодействия. Это обоснованно давней дискуссией о детерминантах поведения человека в обществе и определением того, что первично - материальный (теория рационального выбора) или иррациональный выбор поведения индивида.

Обращение к ценностным основаниям гражданской активности прослеживается у множества современных исследователей. Например, А.Л. Маршак и Л.В. Рожкова отмечают: «В условиях происходящих дезинтеграционных, кризисных процессов меняется структура и иерархия ценностного пространства, происходит утрата единых ценностнонормативных ориентиров. На первый план выходит проблема консолидации общества. Ценностные ориентации являются важнейшим мотиватором поведения индивидов. Поэтому исследуя динамику ценностей и ценностных ориентаций можно понять глубинные когнитивные процессы и дать прогноз трансформации поведенческих стратегий индивидов» [Маршак, 2020, с. 27].

А.С. Оздиев полагает, что «ценностные ориентации представляют собой социологическую категорию, определяющую устойчивое и социально обусловленное избирательное отношение к объектам как социальным ценностям, которое формируется на основе потребностей и интересов личности. Специфика ценностных ориентаций заключается в том, что, в отличие от всех остальных ценностных категорий, они наиболее тесно связаны с поведением субъекта, обусловливая его поступки и действия. Основной функцией ценностных ориентаций является регулирование как внешней, так и внутренней активности личности» [Оздиев, 2015, с. 141].

Проблема ценностных оснований представляется нам одной из наиболее значимых в исследовании гражданской активности. Обращаясь к термину «гражданская активность», можно подчеркнуть отсутствие у современных исследователей единого понимания относительно его сути и содержания. В исследованиях современных отечественных социологов и политологов гражданская активность понимается в различных аспектах как процесс, как действие, как личное качество, как гражданская позиция. Множество подходов к интерпретации термина «гражданская активность» приводят к тому, что эмпирические исследования в данной сфере имеют чрезвычайно разнородный характер.

В рамках нашего исследования под гражданской активностью мы будем понимать деятельность индивидов, социальных групп, институтов гражданского общества по достижению общих для большинства целей, основанную на единстве ценностных установок, взаимном доверии, солидарности и ответственности.

Для анализа ценностных оснований гражданской активности обратимся к результатам социологического исследования «Габитус гражданской активности в системе социальных взаимоотношений», проведенного в 2020 году научным коллективом НИУ «БелГУ». В рамках реализации проекта на основе анализа данных массового опроса были обоснованы ключевые тенденции в сфере социальных взаимодействий, взаимоотношений и гражданской активности.

Анализ полученных данных показал, что сегодня детерминирующим фактором отношений в обществе становится социальная разобщенность. Результаты исследования позволили нам констатировать наличие глубокого дефицита консолидирующих ценностей, как результат - граждане не готовы к объединению с другими людьми.

Распределение ответов респондентов относительно доминирующих в обществе ценностей показало, что в обществе превалируют: индивидуализм (83\%), осторожность и осмотрительность (80\%), стремление к богатству (43\%). Разумеется, такие ценности существенно препятствуют включению граждан в социальные взаимосвязи и отношения. Лишь семейно-родственные и дружеские сети признаются подавляющим большинством респондентов в качестве потенциального адресата объединения и обращения за помощью в трудных жизненных ситуациях. 
Существенное негативное влияние на процессы ценностной солидаризации общества оказал социально-гигиенический фактор, роль которого возросла под влиянием пандемии коронавирусной инфекции. Согласно данным проведенного нами опроса, самоизоляция и карантинные меры, предпринятые в связи с пандемией, усилили разобщенность (56 \%), увеличили недоверие к окружающим (55\%), увеличили тревожность в обществе $(93 \%)$.

Результаты исследования позволили отметить, что противоречивость проявляется не только на уровне ценностных ориентаций и установок, но и в мотивации респондентов к участию в решении общественно-значимых проблем и задач, а также готовности к объединению с другими людьми.

Более $70 \%$ опрошенных граждан считают, что жителям необходимо принимать участие в развитии территории проживания. Однако при этом реально участвовать в данном процессе изъявили желание только $47 \%$ опрошенных. А принимали участие лишь 28 \%. Почти треть опрошенных нами граждан отметили, что не хотели бы участвовать в решении проблем своего населенного пункта.

В итоге складывается ситуация, при которой осознаваемая гражданами значимость гражданской активности не переноситься ими в реальные практики социального действия. Усложняется ситуация тем, что те граждане, у которых все же нашлась мотивация к активности (а именно 28 \%), в процессе ее реализации сталкиваются с рядом иных проблем как общественного, так и институционального характера, которые в последствии вынудили их отказаться от какого-либо проявления активизма.

Во-первых, это проблема поиска взаимопонимания и выстраивания диалога между различными участниками процесса гражданской активности, в частности между гражданами, между населением и властью и т.д. Во-вторых, это отсутствие результата от проявления активности. Граждане отметили, что во множестве случаев проблема, для решения которой им приходилось включаться в те или иные формы активности, была не решена либо решена частично.

В целом, анализируя степень заинтересованности населения в решении проблем территории проживания и готовности к объединению для этого с другими людьми, можно выделить несколько моделей поведения граждан:

- рационально-активную (субъектами данной модели являются активные граждане, принимающие участие в различных формах гражданской активности, в рамках данной модели у граждан выражены ценности доверия, взаимной ответственности, территориальной идентичности, развита социетальная мотивация);

- конформистскую (приспособленческую - субъектами данной модели выступают граждане, в чьих ценностных установках доминируют представления о необходимости гражданской активности и участия, однако по разным причинам они не включаются в практики коллективного действия, межличностное и институциональное доверие на низком уровне);

- индивидуалистскую (субъектами данной модели являются граждане, в чьих ценностных установках доминируют индивидуалистические ценности, они не доверяют окружающим, в сложных ситуациях склонны рассчитывать только на себя, в практики гражданской активности готовы включаться только для решения личных проблем).

Подводя итоги исследованию, отметим, что важнейшим свойством современного общества является дефицит солидаристских ценностей, в обществе превалируют индивидуализм, осторожность и осмотрительность по отношению к другим, низкий уровень межличностного и институционального доверия. В то же время преодоление негативных тенденций и вызовов современной внешней среды невозможно без консолидации социума, а значит, необходим поиск источников солидаризации и консолидации, актуальных современным условиям. 


\section{Список литературы}

1. Маршак А.Л., Рожкова Л.В. 2020. Культурная консолидация как инновационная основа развития социальной структуры российского общества. ПОИСК: Политика. Обществоведение. Искусство. Социология. Культура, 3 (80): 27-39.

2. Оздиев О.С. 2015. Ценности и ценностные ориентации как регулятор социальной активности людей. ПОИСК: Политика. Обществоведение. Искусство. Социология. Культура, 3 (50): $137-145$.

\section{References}

1. Marshak A.L., Rozhkova L.V. 2020. Kul'turnaya konsolidatsiya kak innovatsionnaya osnova razvitiya sotsial'noi struktury rossiiskogo obshchestva. [Cultural consolidation as an innovative basis for the development of the social structure of Russian society]. POISK: Politika. Obshchestvovedenie. Iskusstvo. Sotsiologiya. Kul'tura, 3 (80): 27-39.

2. Ozdiev O.S. 2015. Tsennosti i tsennostnye orientatsii kak regulyator sotsial'noi aktivnosti lyudei. [Values and value orientations as a regulator of people's social activity]. POISK: Politika. Obshchestvovedenie. Iskusstvo. Sotsiologiya. Kul'tura, 3 (50): 137-145.

Конфликт интересов: о потенциальном конфликте интересов не сообщалось.

Conflict of interest: no potential conflict of interest related to this article was reported.

\section{ИНФОРМАЦИЯ ОБ АВТОРЕ}

Хрипкова Дианна Вазгеновна, старший преподаватель кафедры социальных технологий и государственной службы Белгородского государственного национального исследовательского университета, г. Белгород, Россия

\section{INFORMATION ABOUT THE AUTHOR}

Diana V. Khripkova, senior lecturer of the Department of Social Technologies and Public Service of the Belgorod National Research University, Belgorod, Russia 